\title{
Injection Effects on Sediment Transport in Closed-Conduit Flows
}

\author{
Deping $\mathrm{CAO}^{1}$, Yee-Meng CHIEW ${ }^{1}$, and Shu-Qing $\mathrm{YANG}^{2}$ \\ ${ }^{1}$ School of Civil and Environmental Engineering, \\ Nanyang Technological University, Singapore; e-mail: cymchiew@ntu.edu.sg \\ ${ }^{2}$ School of Civil, Mining and Environmental Engineering, \\ University of Wollongong, Wollongong, Australia
}

\begin{abstract}
Experiments were conducted to investigate injection effects on sediment transport in closed-conduit flows. The results show that the sediment transport rate essentially remains unchanged when the ratio of the injection velocity and that at boiling, $V_{i} / V_{c r}<10$. However, significant sediment transport rate is observed when $V_{i} / V_{c r}$ increases beyond this limit. In the literature, three semi-empirical models have been developed to relate seepage effects on the sediment transport rate. The experimentally measured data in the pre- and post-boiling condition (Liu and Chiew 2014, and the present study, respectively) are compared with these models. The results show that the models of Francalanci et al. (2008) and Nielsen et al. (2001) perform poorly in predicting injection effects on the sediment transport. Although Yang's (2013) model could reasonably predict the influence of injection on the sediment transport rate in the post-boiling condition, it similarly fails when applied to the pre-boiling condition.
\end{abstract}

Key words: sediment transport, injection, quick condition, closedconduit flow. 


\section{INTRODUCTION}

Sediment transport is a very complex subject that requires a comprehensive understanding of the interaction between water and geological boundary conditions (Aberle et al. 2012, Ballio and Tait 2012). Consequently, the sediment transport rate in many situations is as yet not accurately predicted. Notwithstanding this, it has been widely investigated in steady, uniform conditions where the vertical velocity is almost zero and the pressure distribution of the flow field is hydrostatic. Since Du Boys (1879) first published his bedload formula more than a century ago, much research has been devoted to the study not only on bed but also suspended sediment transport. With these extensive research works in the intervening years, engineers can now predict sediment transport rate reasonably accurately in a quasi-steady, quasi-uniform rectilinear flow. Notwithstanding this, accurate or even reasonably accurate prediction of sediment transport rates in flow conditions that do not conform to this limited condition still remains a challenge. Such conditions include local scour around a bridge abutment/bridge pier, beach erosion by waves, flows associated with sand boiling or liquefaction that may be induced by an earthquake, etc. The last situation may also take place in the absence of an earthquake, with its occurrence related to the condition when the groundwater table is higher than the adjoining water level in a stream. At that instant, water will flow normally across the permeable bed, inducing seepage flow in the upward direction or injection into the stream. When the injection rate is large enough, the sand particles on the bed may boil, which may lead to significant bank failure or rapid bedform change. Understanding the interaction of groundwater and sediment transport along the coast and river course is essential for managing beach and bank erosion. Sediment transport under boiling condition may lead to significant bank failure or rapid bedform change, for example, during the rapid drawdown of the water depth in a river during the recession of the hydrograph. Such effect and behavior are of interest to both the hydraulic and geophysical communities. Such a phenomenon can be found in both natural rivers and man-made canals, e.g., the lower Boise River Basin, Idaho, Lower Colorado River, USA, Yangtze River, New York canal (Berenbrock 1999; Tang et al. 2009; Carlson and Petrich 1998).

Because of the important effect of seepage on the geomorphological behavior of the fluvial system, many studies have been reported in the literature on the effect of injection on sediment bed instability or the transport rate of sand particles (Meyer et al. 1994, Rao and Sitaram 1999, O'Donnell et al. 2002, Lu and Chiew 2007, Francalanci et al. 2008, Liu 2010, Richards and Reddy 2012, Fujisawa et al. 2013, Liu and Chiew 2014, etc.). 
Rao and Sitaram (1999) carried out experiments to study injection effects on the stability, mobility, and incipient motion of sand-bed particles in a rectangular open channel with a length $3.6 \mathrm{~m}$ and a $2.4-\mathrm{m}$ long seepage zone. They found that injection increases the bed particle stability. O'Donnell et al. (2002) conducted laboratory tests on the effect of increasing seepage flow from a sand bed on sediment transport rates. Experiments were carried out in a re-circulating flume with a length $10 \mathrm{~m}$ and a 3.6-m length seepage zone. They found that at the quick condition, the sediment transport rate will increase by $10-20 \%$ compared with that without injection.

Fujisawa et al. (2013) conducted experiments to investigate the migration velocity of sand particles transported by upward and horizontal seepage flows. They found that when the upward injection flow velocity increased, the hydraulic gradient decreased marginally before boiling occurred, beyond which it decreased rapidly. In addition, the increasing trend of the sand transport velocity was remarkably similar to that of the injection flow velocity, i.e., neither of them did change much before boiling occurred, beyond which they both increased quickly.

Liu and Chiew (2014) studied the effect of injection on sediment transport rate in a horizontal open channel flume that was $30 \mathrm{~m}$ long with a $2-m$ length seepage zone. Their results show that an increase in the injection velocity causes a marginal reduction of the sediment transport rate.

A cursory examination of the related published literature reveals that different researchers hold very different views on injection effects on sediment transport rate in open channel flow. Some opined that injection increases sediment transport rate, while the others found an exact opposite trend. Very few researchers have directly measured the sediment transport rate except for Liu (2010) and Fujisawa et al. (2013). Moreover, the latter only investigated the sediment transport rate in the presence of upward injection and did not consider the combined effects of both the streamwise and injection flows on sediment transport rate. The former, however, did conduct direct measurements of the sediment transport rate.

As injection or suction can noticeably change the sediment transport rate (Liu and Chiew 2012, Cao and Chiew 2014, etc.), some researchers have made attempts to develop semi-empirical equations for its computation. They generally believed that the boundary shear stress $\tau(=\rho g h S)$ may be used to relate to sediment transport in unsteady and non-uniform flows, but the Shields number $\tau_{*}\left\{=\tau /\left[\left(\rho_{s}-\rho\right) g d\right]\right\}$ needs to be modified $(\tau-$ shear stress, $\rho_{s}$ - sediment density, $\rho$ - fluid density, $g$ - gravitational acceleration, $h$ - water depth, $d$ - particle size, $S$ - energy slope). Amongst them, Francalanci et al. (2008) modified the Shields number by correlating the pressure variation with water density, i.e., a higher pressure corresponds to a higher fluid density, and vice versa. Contrary to the approach of Francalanci 
et al. (2008), who relate the water pressure with the Shields number, Nielsen et al. (2001) used the hydraulic gradient to modify the Shields number.

Recognizing that sediment transport is a near-bed phenomenon, Yang (2005) surmised that all the parameters used to relate to sediment transport should be those that are close to the boundary and that the total boundary shear stress alone is insufficient because the energy used in causing the formation of bed features is not used in transporting the sediment particles. Hence, he proposed the use of $\tau$ and $u *$ (shear velocity related to the grains) in the formula he published. Later, Yang (2013) investigated the influence of the vertical velocity on sediment transport and proposed the concept of an apparent density of sediment particles. He argued that the upward vertical velocity reduces the settling velocity of the sediment particles, which has a similar effect as the reduction of sediment density. He hypothesized that the sediment transport subjected to injection has the same effect as the transport of lightweight materials that can be estimated using existing theorems of sediment transport.

Therefore, it is necessary to conduct some specially designed experiments to test these three published models. As most previous studies were conducted in open channel flows, the water depth at the injection location changes significantly when a large injection rate is introduced. Consequently, to eliminate the effect of the changing water depths, the present study is conducted in a closed conduit to examine whether injection enhances or restrains sediment transport. It is widely accepted that there are many similarities between flows in a rectangular open channel and those in a closed conduit, but the latter eliminate the complicating effect of free surface (Knight et al. 1982).

The main differences between open channel and closed-conduit flows are twofold. First, the former has a free surface while the latter does not. This should not affect significantly the sediment transport as it is mostly correlated with the flow near the particle bed. However, as indicated in the study of Francalanci et al. (2008), injection tends to cause a local depression of the water surface, thus modifying the flow field. This phenomenon is clearly not apparent with a closed-conduit flow. Second, the former is gravity driven while the latter is pressure-driven. Consequently, the absolute pressure acting on the sediment bed in an open channel and a closed conduit may be different. Although a few previous researchers, e.g., Bagnold (1966), have stated that pressure will influence bed transport rate, the effect of pressure on bed sediment mobility is not well-established, as not many other studies have been reported. 


\section{PREVIOUS THEORETICAL MODELS}

Figure 1 shows how a sand bed consisting of spherical particles with diameter $d$ experiences both streamwise and vertical flows in a closed-conduit flow. The bed sediment particles are clearly subjected to the horizontal and vertical forces due to the approach flow and injection, respectively. As discussed in Section 1, there apparently are just three methods in published literature (Nielsen et al. 2001, Francalanci et al. 2008, Yang 2013) that may be used to compute the volumetric sediment transport rate, $q_{t}$, associated with such a condition.

The first method is that introduced by Nielsen et al. (2001), who investigated the effect of suction on sediment mobility both experimentally and analytically by using a modified Shields number (Nielsen 1997) to account for its effect as follows

$$
\tau_{*}^{\prime}=\frac{u_{*}^{2}\left(1-\alpha \frac{V_{i}}{u_{*}}\right)}{g d_{50}\left(s-1-\gamma \frac{V_{i}}{K}\right)},
$$

where $u *$ is shear velocity and can be taken to be the same as that related to the grains; $\alpha$ and $\gamma$ are dimensionless coefficients, which represent the strength of shear stress increase and the downward drag, respectively; $V_{i}$ is the average injection velocity, $V_{i}=Q_{i} / A_{i}, Q_{i}$ and $A_{i}$ are injection flow rate and cross-sectional area of the injection zone, respectively; $K$ is coefficient

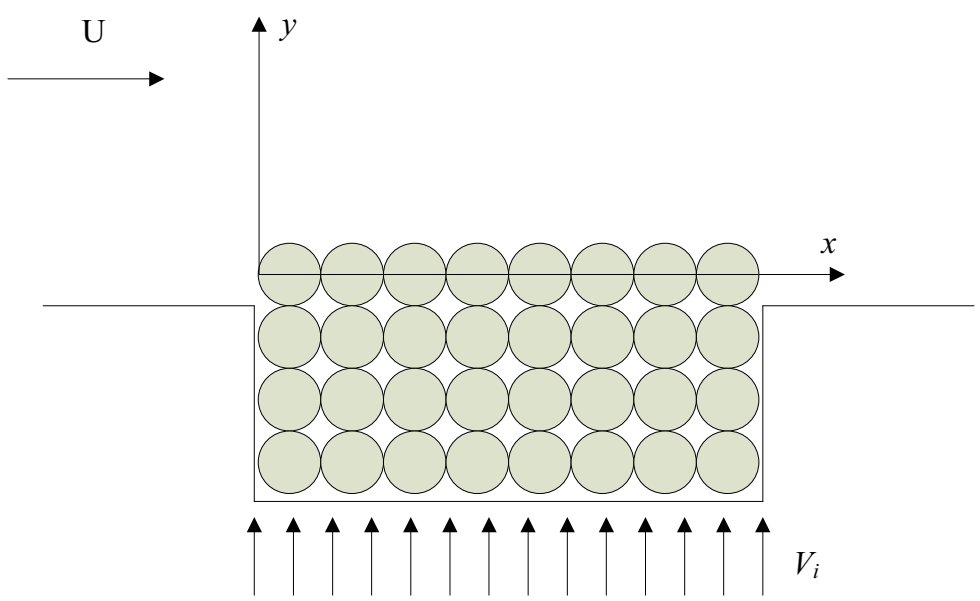

Fig. 1. Sketch of sand bed subject to both streamwise and vertical flows. 
of permeability; $d_{50}$ is the median grain size. In the present study, we have extended the use of Eq. 1 to the case of injection. By referring to the study of Conley (1993) and Martin and Aral (1971), Nielsen found that $\alpha$ and $\gamma$ may be taken as 16 and $0.35 \sim 0.4$, respectively. In this study, $\alpha=16$ and $\gamma=0.4$ are adopted and Eq. 1 is used to fit the present experimental data.

The second method is that proposed by Francalanci et al. (2008), who utilized the modified equation of Meyer-Peter and Müller (1948) given in Wong and Parker (2006) to fit their experimental data as shown in Eq. 2

$$
q_{t}=4.4158 \times\left(\tau_{*}^{\prime}-\tau_{*_{c r}}\right)^{1.5},
$$

where $q_{t}$ is volumetric sediment transport rate; $\tau_{*}^{\prime}$, which denotes the Shields number due to skin friction, may be computed by using

$$
\tau_{*}^{\prime}=\frac{\rho u_{*}^{2}}{\left[\rho_{s}-\rho\left(1+\frac{V_{i}}{K}\right)\right] g d_{50}}
$$

and $\tau_{* r}$ is critical Shields number for the onset of sediment motion in the presence of seepage, which may be evaluated using the following equation proposed by Cheng and Chiew (1999),

$$
\frac{\tau_{*_{c r, s}}}{\tau_{*_{c r, o}}}=1-\left(\frac{V_{i}}{V_{c r}}\right)^{m},
$$

where $\tau_{*_{c r, s}}$ and $\tau_{*_{c r, o}}$ denote the critical Shields number with and without seepage, respectively; $V_{c r}$ is critical injection velocity, which will cause the quick condition for the sediment particles; $m$ is 1-2 depending on the characteristics of flow and sediment particles; $m$ is chosen to be 1 in the present study.

In the third method, Yang (2005) modified Bagnold's (1966) equation of sediment transport rate as follows

$$
q_{t}=k\left(\frac{\rho_{s}}{\rho_{s}-\rho}\right) \tau_{o}\left(\frac{u_{*}^{2}-u_{*_{c}}^{2}}{\omega}\right),
$$

where $k$ is the empirical constant (Yang 2007); $\tau_{0}$ is the bed shear stress in the absence of seepage; $u_{*_{c}}$ is the critical shear stress of the sand particle; $\omega$ is the settling velocity of the sand particle, which may be calculated as follows:

$$
C_{d} \frac{\pi d^{2}}{4} \frac{\rho \omega^{2}}{2}=\frac{\pi d^{3}}{6} g\left(\rho_{s}-\rho\right),
$$

where $C_{d}$ is the drag coefficient without injection. 
Yang (2013) believes that introducing an injection velocity $V_{i}$ will reduce the fall velocity $\omega$ to $\omega-V_{i}$, and the same fall velocity may be computed if the diameter of the sediment particle were to remain unchanged while the particle density changes to $\rho_{s}^{\prime}$, thus leading to

$$
C_{d}^{\prime} \frac{\pi d^{2}}{4} \frac{\rho\left(\omega-V_{i}\right)^{2}}{2}=\frac{\pi d^{3}}{6} g\left(\rho_{s}^{\prime}-\rho\right),
$$

where $C_{d}^{\prime}$ is the drag coefficient with injection.

Combining Eqs. 6 and 7, one can get the following relationship

$$
\frac{\rho_{s}^{\prime}-\rho}{\rho_{s}-\rho}=\frac{C_{d}^{\prime}}{C_{d}}\left(1-\frac{V_{i}}{\omega}\right)^{2}
$$

where $C_{d}^{\prime} / C_{d}$, as a first approximation, $\approx 1$. By combining Eqs. 5 and 8 , the following equation is obtained

$$
q_{t}(Y)=k\left[\frac{\rho}{\rho_{s}-\rho}\left(\frac{1}{1-Y}\right)^{2}+1\right] \tau_{o} \frac{u_{*}^{2}-u_{* c}^{\prime 2}}{\omega(1-Y)},
$$

where $q_{t}(Y)$ is the sediment transport rate with injection; $Y=V / \omega=\beta V_{i} / \omega$ and $\beta$ is defined as the ratio of the actual vertical velocity $V$ through the voids of the sand grains and the average injection velocity, $V_{i}$. In theory, it is the inverse of the effective porosity of the sand and depends on its characteristics, e.g., size and distribution of the sand and geometric complexity of the pore space, etc. Because the medium value of the effective porosity of fine sand is 0.33 (McWhorter and Sunada 1977), $\beta$, which is its reciprocal, $\approx 3$ for the present study since fine sand with a median grain size $0.2 \mathrm{~mm}$ is used.

If one assumes that injection has little influence on the streamwise parameters, i.e., $\tau_{o}$ and $u_{*}$ (Yang 2013), the following equations will be true

$$
\frac{q_{t}(Y)}{q_{t}(0)}=\frac{\rho}{\rho_{s}(1-Y)^{3}}+\frac{\rho_{s}-\rho}{\rho_{s}(1-Y)},
$$

where $q_{t}(0)$ is the sediment transport rate without injection. Based on Eq. 10, one may surmise that introducing injection will lead to an increase in sediment transport rate.

The experimental data which will be used to test these 3 methods are presented and discussed in the following section. 


\section{EXPERIMENTAL SETUP AND PROCEDURES}

\subsection{Flume and experiment procedure for sediment transport}

The experiments were conducted in a re-circulating rectangular Perspex pipe that is $4.8 \mathrm{~m}$ long, $0.25 \mathrm{~m}$ wide, and $0.25 \mathrm{~m}$ deep. Figure 2, which shows the schematic of the conduit, illustrates how the sand bed is placed in the recess that is $1 \mathrm{~m}$ long and $0.25 \mathrm{~m}$ wide. The recess, which was located $2.4 \mathrm{~m}$ downstream of the conduit inlet, was filled with cohesionless sand particles with $d_{50}=0.2 \mathrm{~mm}$ and geometric standard deviation, $\sigma_{g}=1.29$. The latter is defined as $\sqrt{d_{60} / d_{10}}$ in which $d_{10}$ and $d_{60}$ are the particle size for which $10 \%$ and $60 \%$ are finer by weight, respectively. The specific gravity and porosity of the sand are measured to be 2.65 and 0.466 , respectively, with the ambient temperature of $29^{\circ} \mathrm{C}$. A layer of the same sand was glued on the approach false floor (depth is $0.125 \mathrm{~m}$, thus the water depth is also $0.125 \mathrm{~m}$ ) to ensure uniform roughness. The injection zone with length $=0.1 \mathrm{~m}$ and width $=$

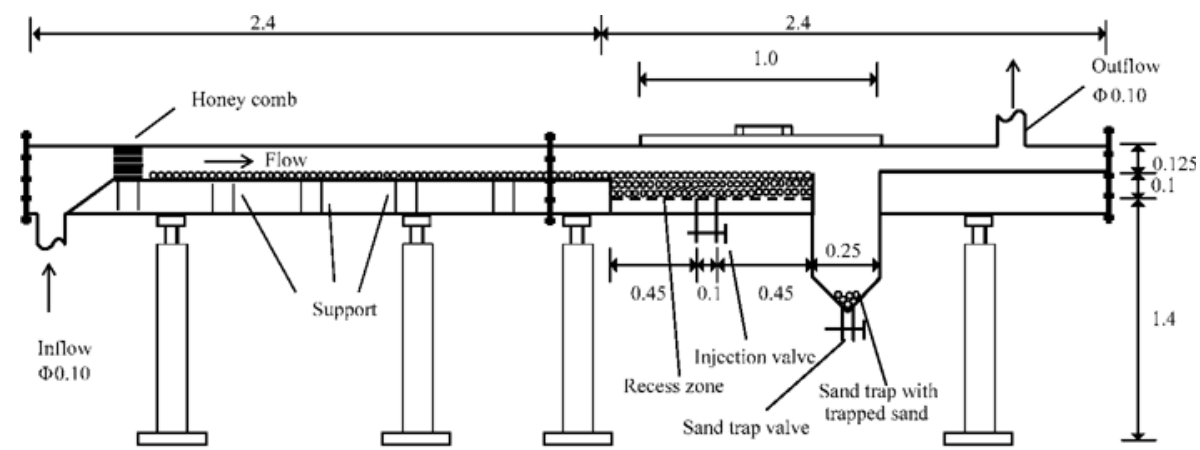

(a)

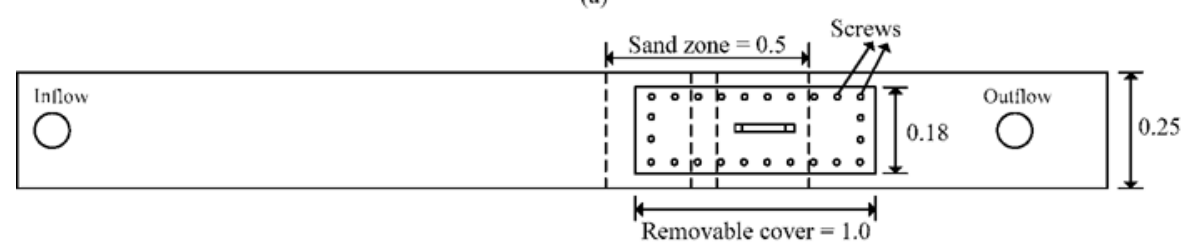

(b)

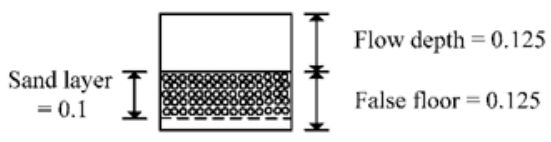

(c)

Fig. 2. Schematic drawing of flume: (a) front view; (b) plan view; and (c) crosssection view (unit: $\mathrm{m}$ ). 
$0.25 \mathrm{~m}$ was located in the sand recess. On top of the recess section, there was an opening with a removable roof to allow access into the conduit for the preparation and execution of the tests. The roof was secured by means of stainless steel screws. Holes with diameter $=6 \mathrm{~mm}$ were drilled onto a Perspex sheet placed beneath the sand bed to obtain a uniform flow inlet. Moreover, a piece of filter cloth was placed between the perforated plate and sand to ensure a uniform injection through the sand bed. A pump was connected to the box under the Perspex sheet to produce injection.

Water, which was stored in a reservoir, was re-circulated into the flume by using two pumps. The bigger pump, also known as the main pump, was able to circulate water at a maximum rate of $10 \mathrm{~L} / \mathrm{s}$. The smaller pump, which was for the injection purpose, had a maximum capacity of $1.5 \mathrm{~L} / \mathrm{s}$. The flow rates in the flume and injection zone, which were each controlled by using a valve, were monitored with two flow meters (the accuracy of both is $\pm 0.01 \mathrm{~L}$ ) and a stop watch. To ensure uniform water distribution, a honeycomb, in the form of small pipes with $20-\mathrm{mm}$ diameter and $10-\mathrm{cm}$ length glued together, was installed at the entrance to the flume.

A transparent sand trap, in the form of a hopper, was placed $0.45 \mathrm{~m}$ downstream of the seepage zone to collect the transported sand particles during the experiment (the same method was used by Sumer et al. (2003) and Pagliara et al. (2011), etc). The sand trap was used to directly measure the bed-load transport rate by collecting the entrained sand within a certain duration. It was connected to a PVC tube with a valve attached to it. The valve was closed during the experiment. After each test, the valve was opened and the collected sand and water were drained to a container. The sand was then dried and weighed to directly measure the sediment transport rate.

The procedure for measuring the sediment transport rate is as follows:

a Remove the roof of the conduit and level the sand surface to the adjacent bed (false floor). Then close the roof and tighten the screws.

- Open the sand trap valve. Turn on the main pump to a very slow flow rate. Wait until no particle is moving to the sand trap anymore, then close the valve and let the water slowly fill the entire flume.

- When the flume is completely filled with water, turn the main pump off and turn the injection pump on. Open the valve to the desired flow rate. When the sand bed has stabilized, adjust the main pump to around $6.8 \mathrm{~L} / \mathrm{s}$. The same main flow rate is used for all the tests. Drain the sand in the hopper.

a Run the experiment for $30 \mathrm{~min}$, during which the flow rates of both pumps are monitored regularly to ensure that they remain constant. At the end of the test, turn both pumps off. 
- Open the sand trap valve to collect the wet sand particles, which are oven-dried at $120^{\circ} \mathrm{C}$. The dried sand is then weighed and the volumetric sediment transport rate calculated.

a A total of 51 experiments have been conducted in this study.

\subsection{Permeability test}

If the injection rate is allowed to increase, the formation of the quick condition or boiling is inevitable. In this study, we need to determine the coefficient of permeability, $K$, and critical injection velocity, $V_{c r}$, for the sediment used in the study for subsequent analyses. A laboratory tool that one may use to evaluate these two variables is through the conduct of a permeability test (ASTM 2006), which is the same as that used in Fujisawa et al. (2013). To this end, the standard permeability test based on the method stipulated in ASTM (2006) was conducted with this objective in mind.

The experimental results obtained from the permeability test are plotted in Fig. 3, which clearly show that when the injection velocity, $V_{i}$, exceeds $0.0324 \mathrm{~cm} / \mathrm{s}$, a distinct gradient change is detected, invalidating the linearity inferred in Darcy's law. This point is defined as the critical seepage velocity at which boiling just occurs for a given sand, $V_{c r}$, and is found to be

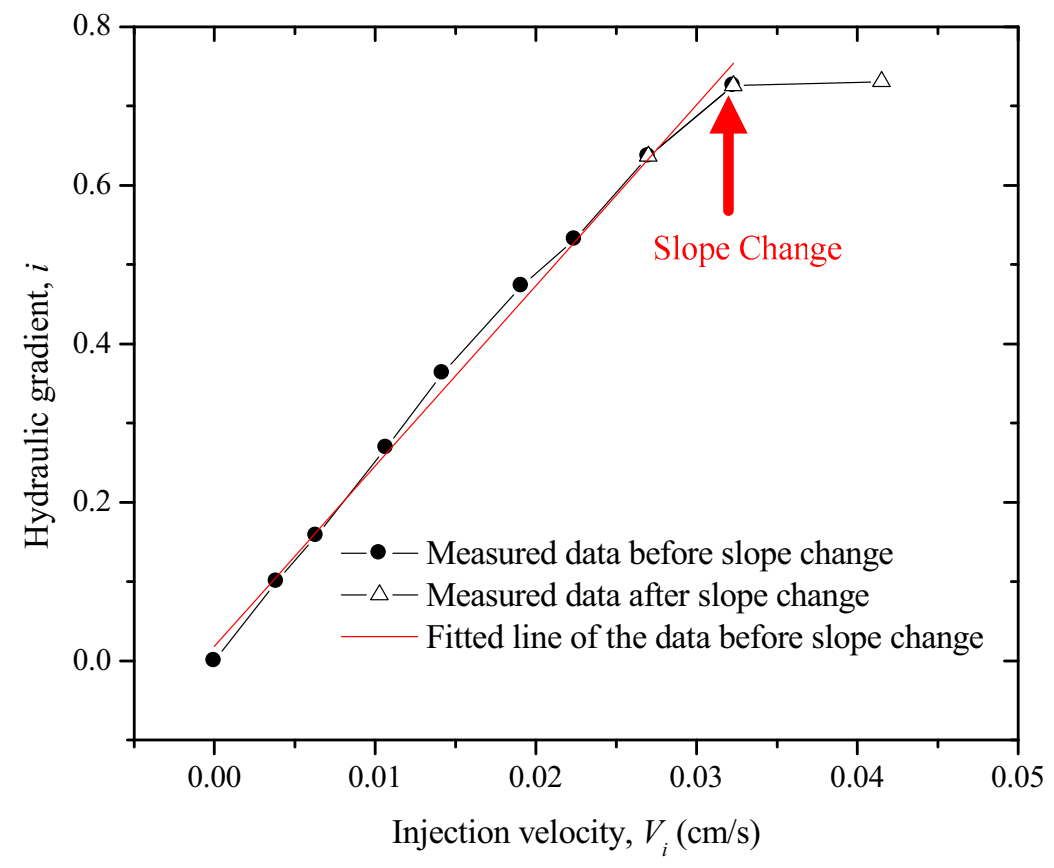

Fig. 3. Permeability test result. 
$0.0324 \mathrm{~cm} / \mathrm{s}$. When $V_{i}<V_{c r}$, the experimental data clearly show a linear relationship with the pressure gradient and injection velocity, as predicted by Darcy's law. The slope of the straight line fitted to the experimental data yields $K \approx 4.0 \mathrm{E}-4 \mathrm{~m} / \mathrm{s}$ (temperature $29^{\circ} \mathrm{C}$ ).

\section{EXPERIMENTAL RESULTS AND DISCUSSION}

\subsection{Experimental results}

Table 1 shows the test conditions and measured sediment transport rates for all the tests. It must be stated at the outset that the main flow rate $Q_{o}$ used in the study is $6.8 \mathrm{~L} / \mathrm{s}$, which corresponds to the computed approach shear velocity ratio, $u *_{o} / u_{*_{c o}}=0.98$ (without injection), in which $u_{*_{o}}$ is undisturbed approach shear velocity, and $u_{*_{c o}}$ is critical shear velocity for bed sediment

Table 1

Test conditions and experimental data $\left(Q_{o}=6.8 \mathrm{~L} / \mathrm{s}, u_{*_{o}} / u_{*_{c o}}=0.98\right)$

\begin{tabular}{|c|c|c|c|c|}
\hline $\begin{array}{c}\text { Test number } \\
\text { (Series A) }\end{array}$ & $\begin{array}{c}\text { Injection rate } \\
Q_{i}\left[\mathrm{Ls}^{-1}\right]\end{array}$ & $\begin{array}{c}\text { Sand collected } \\
g\end{array}$ & $\begin{array}{c}\text { Injection velocity } \\
V_{i}\left[10^{-2} \mathrm{~ms}^{-1}\right]\end{array}$ & $\begin{array}{c}\text { Sediment } \\
\text { transport rate } \\
q_{t}\left[10^{-9} \mathrm{~m}^{2} \mathrm{~s}^{-1}\right]\end{array}$ \\
\hline$(1)$ & $(2)$ & $(3)$ & $(4)$ & $(5)$ \\
\hline 1 & 0.000 & 1.2 & 0.000 & 1.00 \\
2 & 0.015 & 0.9 & 0.058 & 0.75 \\
3 & 0.016 & 1.8 & 0.063 & 1.50 \\
4 & 0.016 & 1.5 & 0.066 & 1.25 \\
5 & 0.017 & 0.2 & 0.069 & 0.17 \\
6 & 0.023 & 2.3 & 0.093 & 1.92 \\
7 & 0.024 & 0.7 & 0.097 & 0.58 \\
8 & 0.025 & 1.2 & 0.101 & 1.00 \\
9 & 0.033 & 2 & 0.132 & 1.67 \\
10 & 0.034 & 1.2 & 0.136 & 1.00 \\
11 & 0.039 & 1.4 & 0.154 & 1.17 \\
12 & 0.044 & 1.1 & 0.175 & 0.92 \\
13 & 0.047 & 2.2 & 0.186 & 1.84 \\
14 & 0.047 & 1.2 & 0.187 & 1.00 \\
15 & 0.049 & 1.5 & 0.197 & 1.25 \\
16 & 0.057 & 2.1 & 0.227 & 1.75 \\
17 & 0.064 & 2.1 & 0.257 & 1.75 \\
18 & 0.068 & 0.8 & 0.272 & 0.67 \\
19 & 0.068 & 0.7 & 0.273 & 0.58 \\
\hline
\end{tabular}

to be continued 
Table 1 (continuation)

\begin{tabular}{|c|c|c|c|c|}
\hline (1) & (2) & (3) & (4) & (5) \\
\hline 20 & 0.077 & 3.2 & 0.308 & 2.67 \\
\hline 21 & 0.078 & 3.6 & 0.310 & 3.01 \\
\hline 22 & 0.079 & 2.5 & 0.317 & 2.09 \\
\hline 23 & 0.083 & 5.4 & 0.331 & 4.51 \\
\hline 24 & 0.084 & 7.3 & 0.337 & 6.10 \\
\hline 25 & 0.086 & 5.6 & 0.343 & 4.68 \\
\hline 26 & 0.088 & 2.7 & 0.350 & 2.26 \\
\hline 27 & 0.092 & 17.7 & 0.369 & 14.79 \\
\hline 28 & 0.095 & 6 & 0.379 & 5.01 \\
\hline 29 & 0.097 & 5.2 & 0.388 & 4.34 \\
\hline 30 & 0.101 & 12.1 & 0.404 & 10.11 \\
\hline 31 & 0.102 & 12.7 & 0.409 & 10.61 \\
\hline 32 & 0.103 & 11.5 & 0.410 & 9.61 \\
\hline 33 & 0.103 & 25.9 & 0.413 & 21.64 \\
\hline 34 & 0.107 & 25 & 0.428 & 20.89 \\
\hline 35 & 0.109 & 14.6 & 0.437 & 12.20 \\
\hline 36 & 0.116 & 12.2 & 0.464 & 10.19 \\
\hline 37 & 0.117 & 15.5 & 0.469 & 12.95 \\
\hline 38 & 0.118 & 9.55 & 0.473 & 7.98 \\
\hline 39 & 0.119 & 9.3 & 0.475 & 7.77 \\
\hline 40 & 0.119 & 21.2 & 0.476 & 17.71 \\
\hline 41 & 0.120 & 20.8 & 0.481 & 17.38 \\
\hline 42 & 0.121 & 21.5 & 0.483 & 17.96 \\
\hline 43 & 0.122 & 22.9 & 0.487 & 19.13 \\
\hline 44 & 0.125 & 10.8 & 0.499 & 9.02 \\
\hline 45 & 0.130 & 34.1 & 0.519 & 28.49 \\
\hline 46 & 0.133 & 21.6 & 0.533 & 18.05 \\
\hline 47 & 0.133 & 18.1 & 0.533 & 15.12 \\
\hline 48 & 0.134 & 23.6 & 0.535 & 19.72 \\
\hline 49 & 0.134 & 14.6 & 0.535 & 12.20 \\
\hline 50 & 0.135 & 13.1 & 0.541 & 10.94 \\
\hline 51 & 0.148 & 20.2 & 0.591 & 16.88 \\
\hline
\end{tabular}

Note: The data in columns 2, 3, and 5 are measured directly in the experiment, while $V_{i}$ is calculated by using $V_{i}=Q_{i} / A_{i}$, where $A_{i}$ is cross-sectional area of the injection zone. The Reynolds number $\mathrm{R}$ for all the experiments is 36266 , which shows that the flow is turbulent, where $\mathrm{R}=U_{0} D_{H} / v, U_{0}=Q_{o} / A, Q_{o}$ and $A$ are the main flow rate and area of cross section of the conduit, respectively; $v$ is kinematic viscosity, $D_{H}$ is hydraulic diameter, and $D_{H}=4 A / P$. 
entrainment without injection. The detailed method used to calculate $u_{*} / u_{*} *_{c o}$ can be found in Cao and Chiew (2014) and Cao et al. (2015) and will not be repeated here. With the shear velocity ratio being slightly less than 1 , the bed sediment particles in the conduit are expected to move slowly (Buffington 1999) and experimental observations verify this expectation. The measured sediment transport rate without injection, $q_{t}=1 \times 10^{-9} \mathrm{~m}^{2} / \mathrm{s}$. The case without injection is the baseline condition and the rest of the data with injection are compared with it.

The ratio between the sediment transport rate with and without injection, $q_{t}(Y) / q_{t}(0)$, is plotted as a function of the injection intensity (defined as the ratio between the injection velocity, $V_{i}$, and critical seepage velocity, $V_{c r}$ ), $V_{i} / V_{c r}$, for the data from Liu and Chiew (2014) conducted in an open channel flow and those from the present study in Fig. 4. It must be stated that the results are plotted on a semi-logarithmic curve in order to have a better visual appreciation of the data of Liu and Chiew. If the $V_{i} / V_{c r}$-axis (horizontal axis) were kept as a normal scale, all their data would have been lumped together to almost a single point on the plot. It must also be noted that their data were not only collected from tests conducted in an open channel flow but they were also subjected to the "pre-boiling" condition $\left(0 \leq V_{i} / V_{c r}<1\right)$, while those collected in the present study were gathered with tests conducted in the "post-boiling" condition $\left(1<V_{i} / V_{c r}<20\right)$ and a closed-conduit flow.

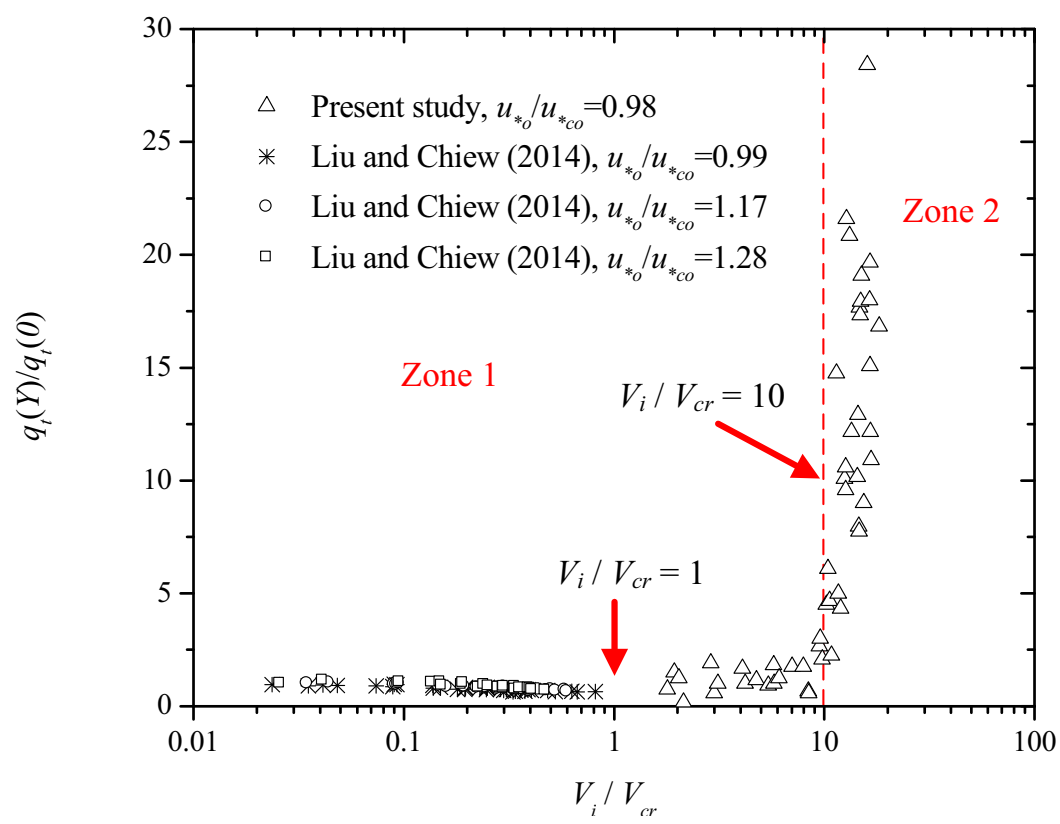

Fig. 4. Effect of injection on bed-load transport rate. 
Figure 4 clearly shows, first of all, that the data collected from these four series of test generally collapse together, and they do not appear to discriminate against shear velocity ratios and the type of flow, i.e., whether open channel or closed-conduit flows, at least within the range of $0.98 \leq u *_{o} / u *_{o c}$ $\leq 1.28$ and $0.02<V_{i} / V_{c r}<20$. In addition, the figure reveals that $q_{t}(Y) / q_{t}(0)$ does not change much when $V_{i} / V_{c r}<10$, especially before the onset of boiling. Even when boiling has occurred, changes to the sediment transport rate still remain negligible. However, the data show that $q_{t}(Y) / q_{t}(0)$ increases abruptly when $V_{i} / V_{c r} \geq 10$. Clearly, one can identify two distinct zones in the figure. Zone 1, which is represented by a low sediment transport rate, occurs for $V_{i} / V_{c r}<10$. The second zone, i.e., Zone 2, is characterized by an abrupt increase of sediment transport rate and occurs when $V_{i} / V_{c r} \geq 10$.

In the present study, four different sand bed mobility behaviors, which are illustrated in Fig. 5, are observed. These behaviors are used to explain the influence of injection on sediment transport rate, particularly the reason why the latter increases dramatically when $V_{i} / V_{c r}$ exceeds 10 . First, before injection is introduced to the seepage zone, Fig. 5a illustrates how the bed surface essentially remains at the same level as the adjacent bed, befitting the expected low sediment transport rate associated with zero injection with a low shear velocity ratio at around the threshold for bed sediment transport. Once injection is introduced, dilation of the sand bed will occur, thus increasing the sand porosity, as is shown in Fig. 5b. As the sand porosity increases, its permeability will correspondingly increase, leading to intensive dilation in the injection zone. As the injection velocity continues to increase, even approaching the quick condition and beyond, the sand particles are lifted out of the seepage zone. This is so because the density or mass of the bed particles has reduced (due to the upward seepage force acting on them) to such an extent that they have exceeded the downward gravity force. Theoretically, the height of the uplifting is dependent on the magnitude of the uplift, which in turn is related to the injection rate. When the uplifted particles have reached the peak of its ascent, they are effectively neutrally buoyant and can easily be entrained by the on-coming flow. These easily entrained "lightweight" or even "zero-weight or sub-zero-weight" sediment particles evidently cause a significant rise in the sediment transport rate.

Based on the results in Fig. 4, it may be surmised that when $V_{i} / V_{c r}>10$, the particles would have been lifted to such an elevation that they are readily entrained downstream by the oncoming flow, resulting in a significant increase of the sediment transport rate. Conversely, the uplift is unable to cause a significant change to the sediment transport rate when $V_{i} / V_{c r}<10$ because of the limited elevation that they have risen to. Notwithstanding this, observations also show that not all the elevated sediment particles were entrained and readily moved downstream. Instead, some of them were re- 


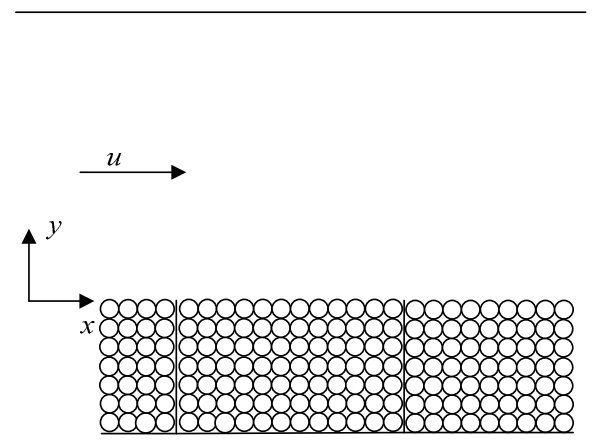

(a)

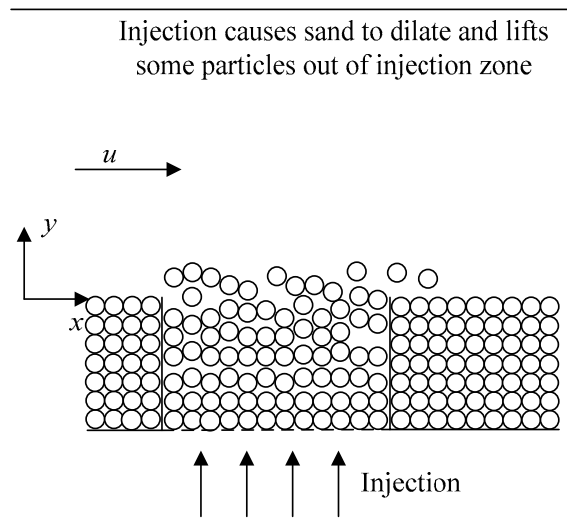

(b)

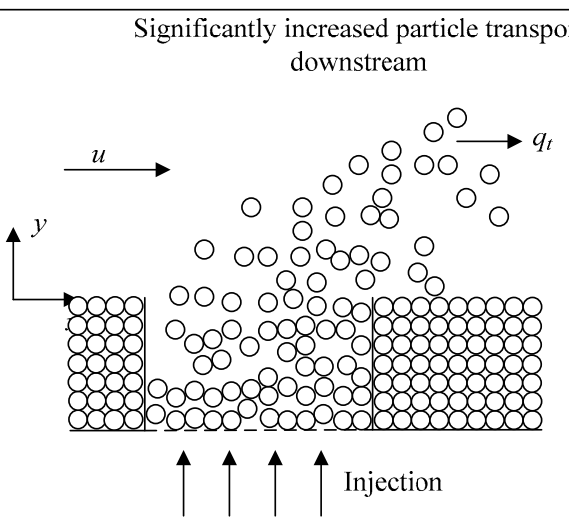

(c)

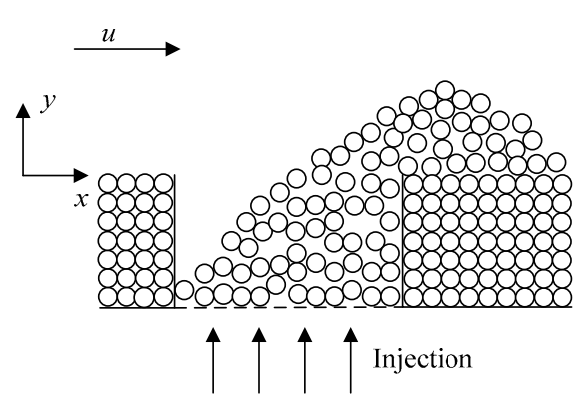

(d)

Fig. 5: (a) Initial situation, (b) dilation of sand, (c) sand is accumulated next to injection area, and $(\mathrm{d})$ bed form after long term running of the experiment.

deposited onto the bed immediately downstream of the seepage zone due to gravity, causing the formation of a heap that resembles a small hill there (see Fig. 5c). When "the critical point", i.e., the intersection of Zones 1 and 2 is reached, many more sediment particles are lifted, transported, and redeposited. Figure $5 \mathrm{~d}$ illustrates the resulting bed morphology after a reasonable period of operation.

Published studies on injections effects, e.g., Cheng and Chiew (1998, 1999), Dey and Nath (2010) and Liu and Chiew (2014), etc., have revealed that injection will increase the flow resistance, decelerate the main flow, 
modify the near-bed velocity, turbulence intensities and Reynold stresses, rendering the velocity and Reynolds stress distribution to deviate from those without injection. Moreover, injection also reduces the effective weight of particles, thus promoting bed sediment mobility, but modifications to the flow tend to promote the stability. In the extreme condition when the bed boils, the very near-bed sediment particles are effectively weightless, causing them to be easily entrained, as is confirmed in the experimental data. Figure 5 clearly illustrates this phenomenon, showing the higher the injection (large post-boiling), the higher (and more) will the sediment particles be lifted, thereby increasing the sediment transport rate significant (see results in Fig. 4).

\subsection{Comparison of the data with different models}

In this section, the data in both the pre-boiling and post-boiling conditions are compared with those computed using the published models. First, Liu and Chiew's (2014) data, which are subjected to the pre-boiling condition, are compared with the computed results by using the three models described in Section 2 in Fig. 6. Unlike that plotted in Fig. 4, the present figure is plotted with the sediment transport rate ratio as a function of $Y$. This is necessary because all the three methods discussed in this paper adopted $Y$ instead of

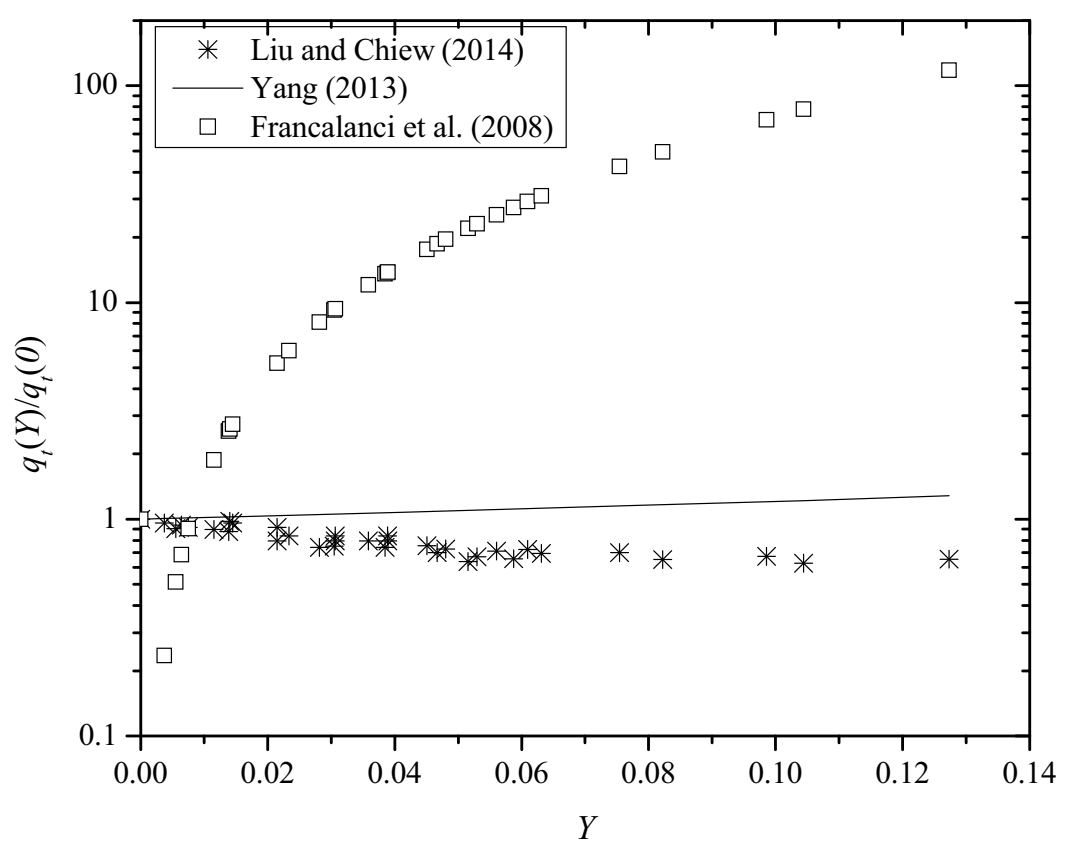

Fig. 6. Liu and Chiew's (2014) data fitted with previous theoretical models. 


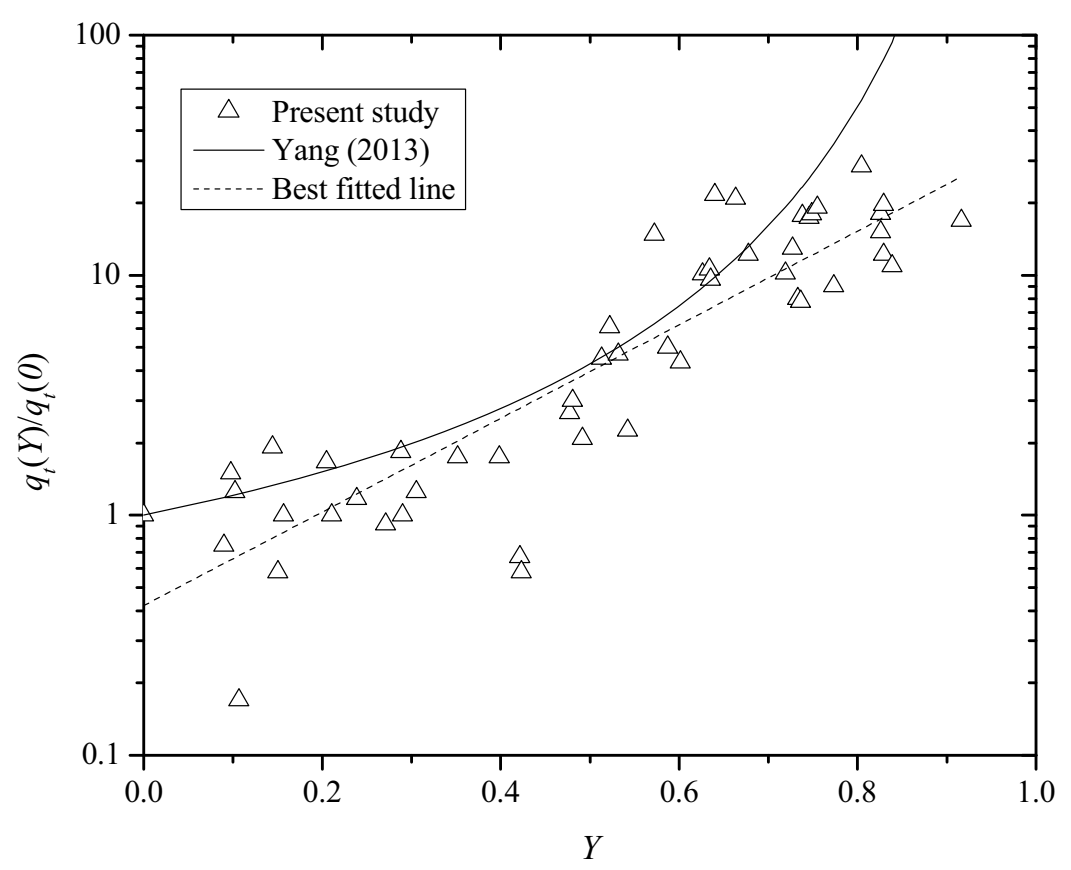

Fig. 7. Comparison of injection effects on sediment transport rate between Yang's (2013) model and measured data.

$V_{i} / V_{c r}$ as the independent variable. It should be noted that only the figure with the data of $u_{*_{o}} / u_{*_{c o}}=0.99$ amongst the three groups of data from Liu and Chiew (2014) has been used in the comparison in order to avoid repetition, as the other two sets of data yield a very similar pattern. Another noteworthy point is that Nielsen et al.'s (2001) model is not shown in Fig. 6 because the shear stress excess, $\left(\tau_{*}^{\prime}-\tau_{*_{c r}}\right)$, is calculated to be negative using his model and $q_{t}$ would all be zero. Moreover, Fig. 6 shows that both Yang's (2013) and Francalanci et al.'s (2008) models predict that injection enhances the sediment transport rate while Liu and Chiew's (2014) result shows a slightly decreasing trend, although the prediction using the model of Yang (2013) performs much better than that of Francalanci et al. (2008).

The present measured data, which relate to the post-boiling condition, are compared with the same three semi-empirical models. Using Yang's (2013) model, the ratio between the sediment transport rate with and without injection, $q_{t}(Y) / q_{t}(0)$, is plotted against $Y$ in Fig. 7. It can be seen that Yang's model fits the data reasonably well. It must be stated that the $\beta$-value of 3 , as was discussed earlier, is used in the computation. Moreover, the fall velocity, $\omega$, is computed to be $0.019 \mathrm{~m} / \mathrm{s}$ by using Cheng's (1997) formula, 


$$
d_{*}=\left(\frac{\Delta g}{v^{2}}\right)^{\frac{1}{3}} d
$$

where $\Delta=\frac{\rho_{s}-\rho}{\rho}$ and $d^{*}$ is dimensionless particle diameter.

$$
\frac{\omega d}{v}=\left(\sqrt{25+1.2 d_{*}^{2}}-5\right)^{1.5}
$$

It is important to note that although Yang's (2013) method does compare reasonably well with the present experimental result, the figure shows that it still overestimates the data when compared with the empirically best fitted curve. A possible cause of the discrepancy may be the assumption made in Yang's (2013) derivation of his formula in that he has neglected the influence of injection on the streamwise parameters, such as $\tau_{o}$ and $u *$. Clearly, this assumption is erroneous because many published data, e.g., Cheng and Chiew (1999), Cao et al. (2015), etc., have categorically shown that both the average and fluctuating components of the velocity change in the presence of both injection and suction.

Figure 8 shows the results computed using the method proposed by Francalanci et al. (2008) and Nielsen et al. (2001). It clearly shows that their prediction deviates significantly from the measured data and the accuracy of both models is much worse when compared with that of Yang (2013), as shown in Fig. 7. For example, when $Y=0.3$, the method of Francalanci et al. (2008) overestimates injection effects on the sediment transport rate by about 3000 folds. By comparing the methods of Francalanci et al. (2008) and Nielsen et al. (2001), however, the result in Fig. 8 reveals that the latter performs even poorer as it overestimates injection effects on the sediment transport rate by even more than that estimated with the method of Francalanci et al. (2008) when $Y>0.25$. When $Y<0.2$, on the other hand, Nielsen's method performs better although both these methods still are inferior to the approach of Yang (2013). Additionally, the glaring flaw of the methods of both models is that the models of Francalanci et al. (2008) and Nielsen et al. (2001) resulted in a hyperbolic function with a point of discontinuity that occurs at $Y=0.102$ and 0.201 , respectively. At these points, the sediment transport rate approaches either $+\infty$ or 0 . The reason for this discrepancy is that $\tau_{*}^{\prime} \rightarrow$ either $+\infty$ or $-\infty$ based on Eqs. 3 and 1, respectively, rendering $q_{t} \rightarrow+\infty$ or 0 , respectively, according to Eq. 2 .

In summary, for both the pre- and post-boiling conditions, the prediction using the models of Francalanci et al. (2008) and Nielsen et al. (2001) deviates significantly from the experimentally measured data. In comparison, the model of Yang (2013) performs much better, especially for the post- 


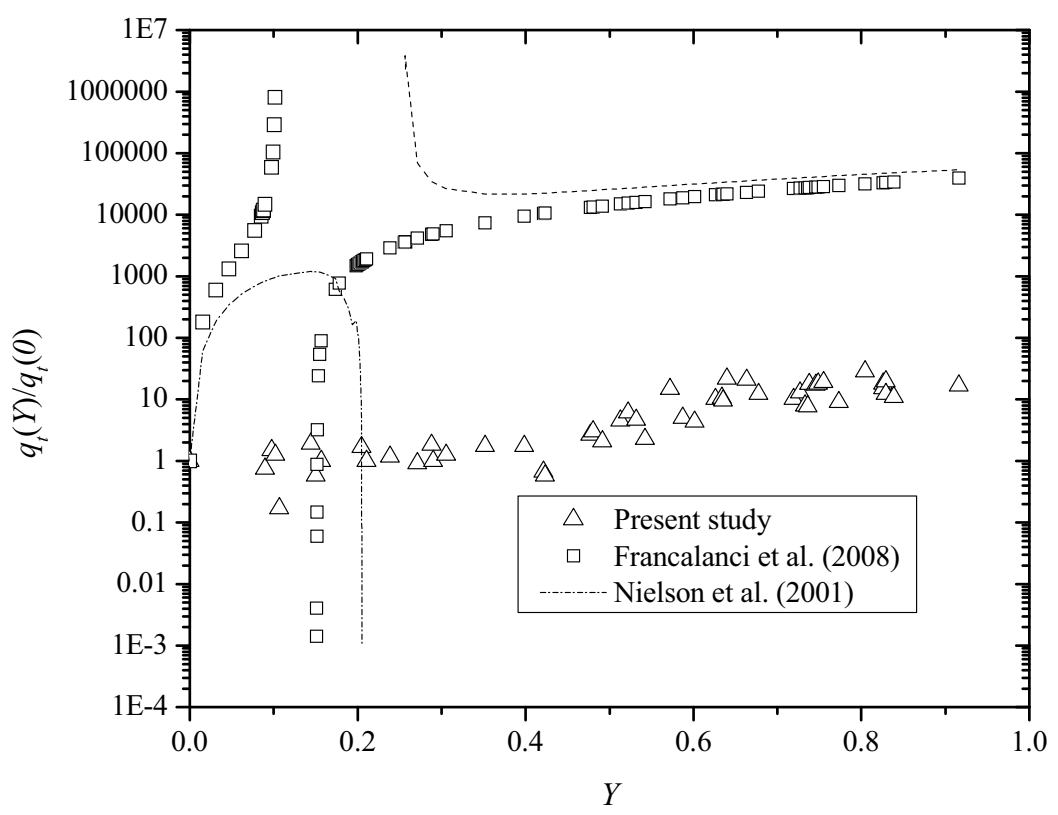

Fig. 8. Comparison of injection effects on sediment transport rate between the models of Francalanci et al. (2008), Nielsen et al. (2001), and measured data.

boiling condition but it is not as good for the pre-boiling condition. Further modification of the model by incorporating the effect of injection on the shear stress is necessary in order to get a better result.

\section{CONCLUSIONS}

This paper explores how the vertical bed injection affects the sediment transport rate in closed-conduit flows. The experimental results show that the sediment transport rate $q_{t}$ does not change much with increasing injection velocity when $V_{i} / V_{c r}<10$, while it increases abruptly as the injection flow continues to increase. The significant increase is attributed to the substantial upward force due to injection at this velocity range, lifting the particle to a higher elevation to be readily transported by the oncoming flow.

By adopting the concept of an apparent particle density, Yang (2013) developed a model to account for injection effects on sediment transport rate. Some other researchers (Francalanci et al. 2008, Nielsen et al. 2001) also have developed semi-empirical models to incorporate the effect of injection on sediment transport rate by modifying the form of Shields parameter or the critical shear velocity.

Both the experimentally measured data in the pre- (data from Liu and Chiew (2014) and $0 \leq V_{i} / V_{c r}<1$ ) and post-boiling condition (data from the 
present study and $\left.1<V_{i} / V_{c r}<20\right)$ are compared with the three published models. The results show that the models of Francalanci et al. (2008) and Nielsen et al. (2001) could not predict injection effects on the sediment transport. Although Yang's (2013) model could reasonably predict the influence of injection on the sediment transport rate in the post-boiling condition, it similarly fails when applied to the pre-boiling condition.

Acknowledgement. This research is conducted under a project sponsored by Singapore Membrane Technology Centre, Nanyang Environment and Water Research Institute, Nanyang Technological University. The financial support for the research is gratefully acknowledged. The authors also wish to thank the experimental work conducted by Ms Pei Nan and Vera Valencia.

\section{Nomenclature}

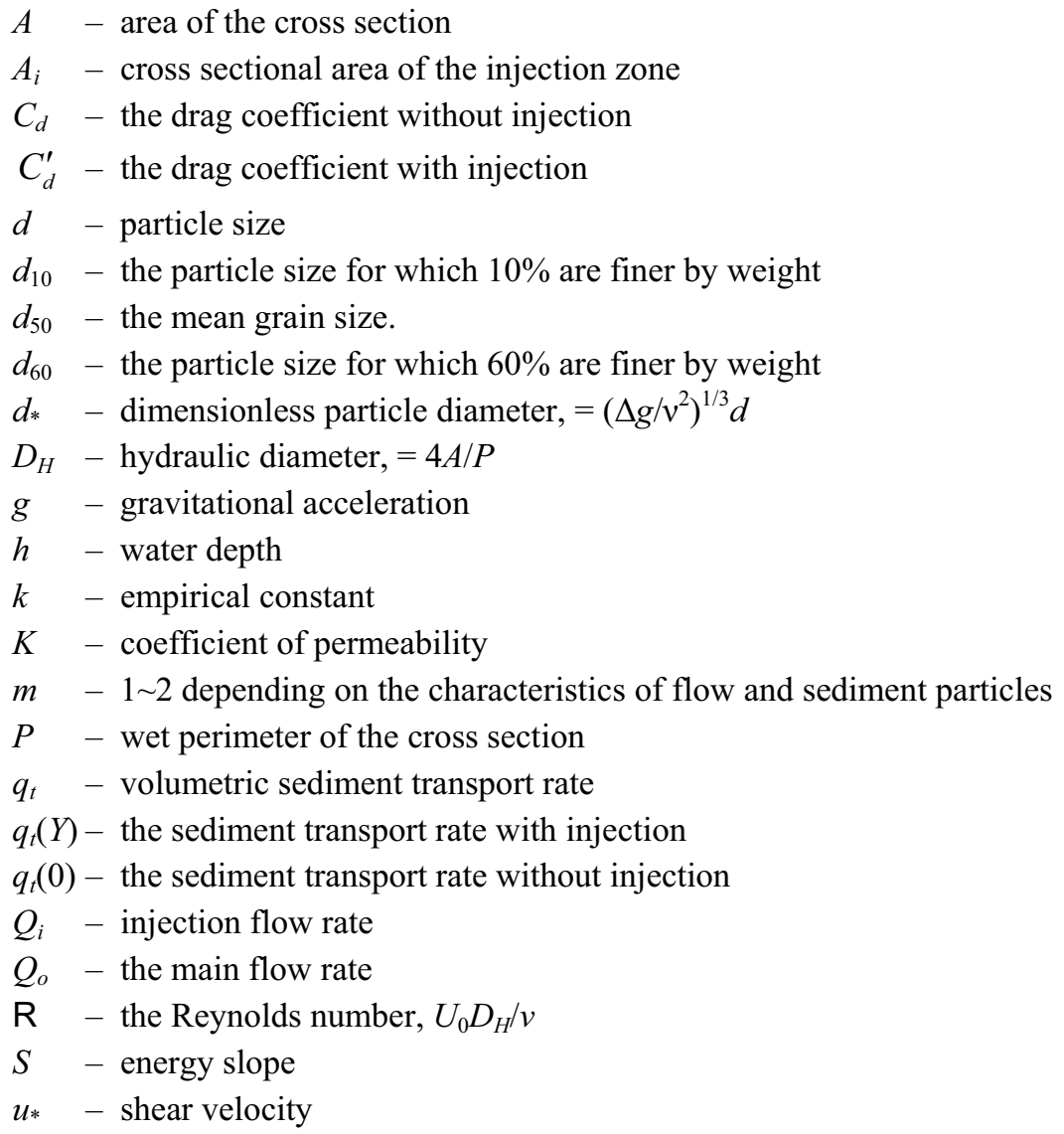


$u_{*_{c}} \quad$ - critical shear velocity of the sand particle with injection

$u_{*}{ }_{c o}$ - critical shear velocity for bed sediment entrainment without injection

$u_{*_{o}} \quad$ - undisturbed approach shear velocity without injection

$V \quad$ - the actual vertical velocity through the voids of the sand grains

$V_{c r}-$ critical injection velocity, which will cause the quick condition for the sediment particles

$V_{i} \quad$ - the average injection velocity, $V_{i}=Q_{i} / A_{i}$

$Y \quad-V / \omega=\beta V_{i} / \omega$

$\alpha-$ dimensionless coefficient, which represents the strength of shear stress increase

$\beta-V / V_{i}$

$\gamma \quad-$ dimensionless coefficient, which represents the downward drag

$v \quad-$ kinematic viscosity

$\rho \quad-$ fluid density

$\rho_{s} \quad-$ sediment density

$\sigma_{g} \quad-$ geometric standard deviation, which is defined as $\sqrt{d_{60} / d_{10}}$

$\tau \quad-$ boundary shear stress, $=\rho g h S$

$\tau_{0} \quad-$ bed shear stress in the absence of seepage

$\tau_{*} \quad-$ the Shields number $=\tau /\left[\left(\rho_{s}-\rho\right) g d\right]$

$\tau_{*_{c r}}-$ critical Shields number for the onset of sediment motion in the presence of seepage

$\tau_{*_{c r, o}}-$ the critical Shields number without seepage

$\tau_{* c r, \mathrm{~s}}-$ the critical Shields number with seepage

$\tau_{*}^{\prime} \quad-$ the Shields number due to skin friction, $=\rho u_{*}^{2} /\left[\rho_{s}-\rho\left(1+V_{i} / K\right)\right] g d_{50}$

$\omega-$ settling velocity of the sand particle

$\Delta=\frac{\rho_{s}-\rho}{\rho}$

\section{References}

Aberle, J., S.E. Coleman, and V.I. Nikora (2012), Bed load transport by bed form migration, Acta Geophys. 60, 6, 1720-1743, DOI: 10.2478/s11600-012-0076-y.

ASTM (2006), Standard test method for permeability of granular soils (constant head): D2434-68. In: Annual Book of American Society for Testing and Materials Standards, Vol. 04.08, 247-252, ASTM, Philadelphia.

Bagnold, R.A. (1966), An Approach to the Sediment Transport Problem from General Physics, Geological Survey Professional Paper, No. 422-I, U.S. Government Printing Office, Washington, D.C. 
Ballio, F., and S. Tait (2012), Sediment transport mechanics, Acta Geophys. 60, 6, 1493-1499, DOI: 10.2478/s11600-012-0074-0.

Berenbrock, C. (1999), Streamflow Gains and Losses in the Lower Boise River Basin, Idaho, 1996-97, Water-Resources Investigations Report 99-4105, U.S. Geological Survey, Reston, USA.

Buffington, J.M. (1999), The legend of A.F. Shields, J. Hydraul. Eng. ASCE 125, 4, 376-387, DOI: 10.1061/(ASCE)0733-9429(1999)125:4(376).

Cao, D.P., and Y.M. Chiew (2014), Suction effects on sediment transport in closedconduit flows, J. Hydraul. Eng. ASCE 140, 5, 04014008, DOI: 10.1061/(ASCE) HY.1943-7900.0000833.

Cao, D.P., Y.M. Chiew, and X.X. Liu (2015), Effect of suction zone length on sediment transport, J. Hydraul. Res. 53, 1, 49-59, DOI: 10.1080/00221686.2014. 928806.

Carlson, R.A., and C.R. Petrich (1998), New York canal geologic cross-section, seepage gain/loss data, and ground water hydrographs: compilation and interim findings, Open file Report, Idaho Water Resources Research Institute and Idaho Department of Water Resources, Boise, USA.

Cheng, N.S. (1997), Simplified settling velocity formula for sediment particle, J. Hydraul. Eng. ASCE 123, 2, 149-152, DOI: 10.1061/(ASCE)0733-9429(1997) 123:2(149).

Cheng, N.S., and Y.M. Chiew (1998), Modified logarithmic law for velocity distribution subjected to upward seepage, J. Hydraul. Eng. ASCE 124, 12, 1235-1241, DOI: 10.1061/(ASCE)0733-9429(1998)124:12(1235).

Cheng, N.S., and Y.M. Chiew (1999), Incipient sediment motion with upward seepage, J. Hydraul. Res. 37, 5, 665-681, DOI: 10.1080/00221689909498522.

Conley, D.C. (1993), Ventilated oscillatory boundary layers, Ph.D. Thesis, University of California, San Diego, USA.

Dey, S., and T.K. Nath (2010), Turbulence characteristics in flows subjected to boundary injection and suction, J. Eng. Mech. ASCE 136, 7, 877-888, DOI: 10.1061/(ASCE)EM.1943-7889.0000124.

du Boys, P. (1879), Le Rhône et les riviérs a lit affouillable, Ann. Ponts Chaussees Mém. Docum. 5, 18, 141-195.

Francalanci, S., G. Parker, and L. Solari (2008), Effect of seepage-induced nonhydrostatic pressure distribution on bed-load transport and bed morphodynamics, J. Hydraul. Eng. ASCE 134, 4, 378-389, DOI: 10.1061/(ASCE)0733-9429(2008) 134:4(378).

Fujisawa, K., A. Murakami, S. Nishimura, and T. Shuku (2013), Relation between seepage force and velocity of sand particles during sand boiling, Geotech. Eng. J. $S E A G S \& A G S S E A$ 44, 2, 9-17.

Knight, D.W., H.S. Patel, J.D. Demetriou, and M.E. Hamed (1982), Boundary shear stress distributions in open channel and closed conduit flows. In: Proc. Euromech 156 - Mechanics of Sediment Transport, Istanbul, Turkey, 33-40. 
Liu, X.X. (2010), Effect of seepage on sediment transport, Ph.D. Thesis, Nanyang Technological University, Singapore.

Liu, X.X., and Y.M. Chiew (2012), Effect of seepage on initiation of cohesionless sediment transport, Acta Geophys. 60, 6, 1778-1796, DOI: 10.2478/s11600-0120043-7.

Liu, X.X., and Y.M. Chiew (2014), Effect of upward seepage on bedload transport rate, Water Sci. Eng. 7, 2, 208-217, DOI: 10.3882/j.issn.1674-2370.2014.02.008.

Lu, Y., and Y.M. Chiew (2007), Seepage effects on dune dimensions, J. Hydraul. Eng. ASCE 133, 5, 560-563, DOI: 10.1061/(ASCE)0733-9429(2007)133:5(560).

Martin, C.S., and M.M. Aral (1971), Seepage force on interfacial bed particles, J. Hydraul. Div. 97, 7, 1081-1100.

McWhorter, D.B., and D.K. Sunada (1977), Ground-water Hydrology and Hydraulics, Water Resources Publs., Highlands Ranch.

Meyer, W., R.L. Schuster, and M.A. Sabol (1994), Potential for seepage erosion of landslide dam, J. Geotech. Eng. ASCE 120, 7, 1211-1229, DOI: 10.1061/(ASCE) 0733-9410(1994)120:7(1211).

Meyer-Peter, E., and R. Müller (1948), Formulas for bed-load transport. In: Proc. 2nd Congress of the International Association for Hydraulic Research, Stockholm, Sweden, 39-64.

Nielsen, P. (1997), Coastal groundwater dynamics. In: Proc. 3rd Coastal Dynamics Conference, June 1997, Plymouth, United Kingdom, ASCE, 546-555.

Nielsen, P., S. Robert, B. Møller-Christiansen, and P. Oliva (2001), Infiltration effects on sediment mobility under waves, Coast. Eng. 42, 2, 105-114, DOI: 10.1016/S0378-3839(00)00051-X.

O’Donnell, C., B.A. O'Connor, and K.H.M. Ali (2002), Effect of seepage flows on sediment transport rates. In: C.A. Brebbia (ed.), Coastal Environment: Environmental Problems in Coastal Regions IV, Vol. 58, DOI: 10.2495/CENV020421.

Pagliara, S., M. Palermo, and I. Carnacina (2011), Expanding pools morphology in live-bed conditions, Acta Geophys. 59, 2, 296-316, DOI: 10.2478/s11600-0100048-z.

Rao, A.R., and N. Sitaram (1999), Stability and mobility of sand-bed channels affected by seepage, J. Irrig. Drain. Eng. ASCE 125, 6, 370-379, DOI: 10.1061/ (ASCE)0733-9437(1999)125:6(370).

Richards, K.S., and K.R. Reddy (2012), Experimental investigation of initiation of backward erosion piping in soils, Géotechnique 62, 10, 933-942, DOI: 10.1680/ geot.11.P.058.

Sumer, B.M., L.H.C. Chua, N.S. Cheng, and J. Fredsøe (2003), Influence of turbulence on bed load sediment transport, J. Hydraul. Eng. ASCE 129, 8, 585-596. DOI: 10.1061/(ASCE)0733-9429(2003)129:8(585).

Tang, H.W., B. Ding, Y.M. Chiew, and S.L. Fang (2009), Protection of bridge piers against scouring with tetrahedral frames, Int. J. Sediment Res. 24, 4, 385-399, DOI: 10.1016/S1001-6279(10)60012-1. 
Wong, M., and G. Parker (2006), Reanalysis and correction of bed-load relation of Meyer-Peter and Müller using their own database, J. Hydraul. Eng. ASCE 132, 11, 1159-1168, DOI: 10.1061/(ASCE)0733-9429(2006)132:11(1159).

Yang, S.Q. (2005), Formula for sediment transport in rivers, estuaries and coastal waters, J. Hydraul. Eng. ASCE 131, 11, 968-979, DOI: 10.1061/(ASCE)07339429(2005)131:11(968).

Yang, S.Q. (2007), Turbulent transfer mechanism in sediment-laden flow, J. Geophys. Res. 112, F1, F01005, DOI: 10.1029/2005JF000452.

Yang, S.Q. (2013), Why cannot sediment transport be accurately predicted. In: Proc. 35th World Congress of the International Association for Hydraulic Research, 1-10.

Received 19 August 2014

Received in revised form 12 February 2015

Accepted 17 February 2015 